\title{
Plasma interleukin-21 levels and genetic variants are associated with susceptibility to rheumatoid arthritis
}

\author{
Youguo Hao ${ }^{1 \dagger}$, Lijun $\mathrm{Xie}^{2 \dagger}$, Jing Xia ${ }^{1}$, Zhen $\mathrm{Liu}^{3,4}$, Baoxiu Yang ${ }^{5}$ and Minqin Zhang ${ }^{5^{*}}$ (D)
}

\begin{abstract}
Background: Rheumatoid Arthritis (RA) is a chronic inflammatory condition characterized by autoantibodies development and an elevated spectrum of pro-inflammatory cytokines. Previous reports highlighted a relationship between IL-21and the pathogenesis of RA. Although elevated IL-21 levels have been reported in RA patients, the association of common IL-21 genetic variants with a predisposition to RA development in the Chinese population lacks.

Materials and methods: Five hundred and fourteen Chinese subjects (healthy controls: 303 and rheumatoid arthritis patients: 211) were enrolled in the study. Clinical data of patients were collected from medical records, and patients were treated as per the guidelines. Common single nucleotide polymorphisms in the IL-21 gene (rs907715, rs2221903, rs2055979 and rs6822844) were genotyped by TaqMan SNPs genotyping method. IL-21 level in plasma of RA patients and healthy subjects was measured by ELISA.

Results: The plasma level of IL-21 was significantly higher in subjects with rheumatoid arthritis relative to healthy controls $(p<0.0001)$. A positive correlation was observed between IL-21 level and DAS28 score, indicating the association of the cytokine with the worsening of the disease (Spearman $r=0.61, p<0.0001$ ). The prevalence of AA genotype (rs2055979) was significantly higher in RA subjects than in the controls $(p<0.0001, \chi 2=34.73, \mathrm{OR}=4.34,95 \% \mathrm{Cl}=2.623$ to 7.219 ). Furthermore, elevated plasma IL-21 was observed in the rs2055979-AA genotype compared to CC type $(p<0.0001)$.
\end{abstract}

Conclusion: IL-21 plays a crucial function in rheumatoid arthritis pathogenesis. IL-21 rs2055979 polymorphism is associated with IL-21 plasma levels and is predisposed to RA development in the Chinese population.

Keywords: Rheumatoid arthritis, Interleukin-21, Polymorphism, Chinese

\section{Introduction}

Autoimmune diseases are characterized by the unregulated activation of the immune system, which attacks and damages various tissue systems. Although various autoimmune disorders are reported worldwide, rheumatoid arthritis (RA) remained the most prevalent one [1]. $\mathrm{RA}$ is a systemic autoimmune disease distinguished by

\footnotetext{
* Correspondence: zhangminqin1234@sina.com

${ }^{\dagger}$ Youguo Hao and Lijun Xie contributed equally to this work.

${ }^{5}$ Department of Chinese Medicine, Wuhan Fourth Hospital, Puai Hospital,

Tongji Medical College, Huazhong University of Science and Technology, Wuhan, Hubei 430033, China

Full list of author information is available at the end of the article
}

the formation of autoantibodies, inflammation, and enlargement of synovial tissues leading to the destruction of bones and cartilages [2]. The involvement of genetic and environmental factors has been demonstrated with the development of RA [3], and the severity of the diseases depends on several risk factors. Although the disease's etiology is not fully understood, it is presumed that multiple inflammatory molecules such as cytokines and chemokines play an essential role in disease progression and pathogenesis $[4,5]$. Various pro-inflammatory cytokines such as TNF- $\alpha$, IL-1 $\beta$, IL-6, and IL-17, have been shown to induce the destruction of cartilages,

C C The Author(s). 2021 Open Access This article is licensed under a Creative Commons Attribution 4.0 International License, which permits use, sharing, adaptation, distribution and reproduction in any medium or format, as long as you give appropriate credit to the original author(s) and the source, provide a link to the Creative Commons licence, and indicate if changes were made. The images or other third party material in this article are included in the article's Creative Commons licence, unless indicated otherwise in a credit line to the material. If material is not included in the article's Creative Commons licence and your intended use is not permitted by statutory regulation or exceeds the permitted use, you will need to obtain permission directly from the copyright holder. To view a copy of this licence, visit http://creativecommons.org/licenses/by/4.0/ The Creative Commons Public Domain Dedication waiver (http://creativecommons.org/publicdomain/zero/1.0/) applies to the data made available in this article, unless otherwise stated in a credit line to the data. 
adjacent bone erosions and increase the severity of the RA pathogenesis [6]. Based on these observations, proinflammatory molecules' regulation has been a crucial targeting approach for developing a possible therapeutic measure against RA. Mainly, inhibition of these inflammatory mediators using the monoclonal antibody approach is of interest that primarily aimed at hindering the synovial inflammation [7]. However, there are many side effects of these monoclonal antibody-based therapies. Additionally, due to prolonged use, these treatment options become ineffective. Therefore, there is always a quest to develop a newer therapeutic approach for the treatment of RA, which can be achieved by venturing into the pathological role of several other inflammatory molecules.

Interleukin-21 (IL-21) cytokine is a member of the IL2 family mainly produced by $\mathrm{CD} 4^{+} \mathrm{T}$ cells and natural killer $\mathrm{T}$ cells (NKT) [8]. However, several reports have also highlighted the production of IL-21 by CD8+ T cells, B cells, macrophages, monocytes, and dendritic cells [9]. IL-21 plays a vital role in the regulation of both innate and adaptive immune systems [10]. Notably, IL21 controls the differentiation of Th17 cells, B cell activation, and immunoglobulins production [11-13]. The role of IL-21 in the pathogenesis of RA is poorly understood. Elevated levels of IL-21 has been demonstrated in the synovial tissue of RA patients [14, 15]. Further, in the experimental arthritis model, the blockade of IL-21/ IL-21 receptor pathways significantly improved disease severity [16], suggesting an essential role of IL-21 in disease pathogenesis. Increased IL-21 has also been associated with higher chances of osteoclastogenesis in humans and mice [15].

In humans, the gene encoding IL-21 is located at the long arm of the fourth chromosome (q26-27). IL-21 gene spans about $8.44 \mathrm{~kb}$ of DNA and consists of six exons and five introns. Various single nucleotide polymorphisms (SNPs) have been reported (https://www. ncbi.nlm.nih.gov/SNP/snp_ref.cgi?locusId=59067). Association of different SNPs with autoimmune disorders such as systemic lupus erythematosus [17], graves disease [18], and inflammatory bowel disease $[19,20]$ have been documented. Various reports have shown a significant association of IL-21 polymorphisms and RA in different populations such as Netherlanders [21], Algerian [22], Columbian [19]. A recent meta-analysis with nine studies [23] demonstrated decreased susceptibility of subjects with IL-21 rs6822844 mutation against RA development. Although the association of IL-21 polymorphisms with RA has been studied in different populations, it has not been explored in the Chinese community. The present study is the first to investigate the possible role of IL-21 polymorphisms in the Chinese cohort.
In the present study, we performed hospital-based case-control research to decipher the role of IL-21 in RA pathogenesis and clinical severity. Furthermore, four common SNPs were genotyped and explored a possible association between IL-21 polymorphisms and predisposition to RA development in the Chinese population.

\section{Materials and methods Study population}

Two hundred eleven rheumatoid arthritis patients (156 females and 55 males) were recruited in the present study from January 2018 to December 2019. All patients visited or admitted in the Department of Rehabilitation, Shanghai Putuo People's Hospital rheumatology division of the hospital and fulfilled the 2010 criteria for American College of Rheumatology/European League against Rheumatism criteria for the classification of RA [24] were enrolled in the study. The mean age of patients was $42.9 \pm 13.5$ years, and the duration of diseases was $18.3 \pm 9.4$ months. The exclusion criteria included hypo or hyperthyroidism, diabetes, other autoimmune disorders, chronic liver failure, acute/chronic diarrhea, and congestive heart failure. Three hundred three healthy controls hailing from similar geographical areas, with a mean age of $46.1 \pm 18.3$ years, were included in the study. RA patients' various clinical data, such as numbers of swollen and tender joints, disease activity score (DAS 28), and swollen joints count (SJC) were collected from medical records. Further, based on DAS28 scores, patients were sub-grouped into low (DAS 28, <3.2), intermediate (DAS 28, 3.2-5.1), and high (DAS 28,>5.1), as per the classification criteria for disease activity by European League against Rheumatism (EULAR) [25]. Different biochemical parameters such as $\mathrm{C}$-reactive protein (CRP), rheumatoid factor (RF), erythrocytic sedimentation rate (ESR), and antibodies to cyclic citrullinated peptides (anti-CCP antibodies) were also examined. All patients were treated with disease-modifying anti-rheumatic drugs (DMARDs) alone or combined with glucocorticoids (GCs). Details of treatments are shown in Table 2. The study was carried out according to the Declaration of Helsinki on ethical principles for medical research involving human subjects [26]. The study protocol was approved by the Institutional Human Ethical Committee of Shanghai Putuo People's Hospital (PTRM YY20200826), and written informed consent was obtained from each participant.

\section{Collection of plasma}

About $4 \mathrm{~mL}$ of intravenous blood was collected from each participant with anti-coagulant at the time of enrollment. Plasma was separated after centrifuging blood at $2500 \mathrm{rpm}$ for $15 \mathrm{~min}$ and stored at $-20^{\circ} \mathrm{C}$ until further use. 


\section{Isolation of genomic DNA}

According to the manufacturer's instructions, total genomic DNA was isolated from $200 \mu \mathrm{L}$ of whole blood by using GenElute Blood Genomic DNA Kit (Merck). In brief, about $200 \mu \mathrm{L}$ of whole blood samples were lysed with lysing solution with proteinase $\mathrm{K}$ at $55^{\circ} \mathrm{C}$ for 10 min. The lysed cells were loaded in the DNA isolation column and centrifuged at $6500 \mathrm{~g}$ for $1 \mathrm{~min}$. Subsequently, the column was washed twice with wash buffer. The membrane-bound DNA was eluted with elution buffer after centrifugation at $6500 \mathrm{~g}$ for $1 \mathrm{~min}$. The isolated genomic DNA was stored at - 20 degrees until further use.

\section{Genotyping of IL-21 polymorphisms}

A total of four SNPs (rs907715, rs2221903, rs2055979, and rs6822844) were typed by TaqMan SNPs genotyping method. Predesigned SNP genotyping assays kit were procured from Thermo Fisher Scientific and used to assess enrolled subjects' genotype. Details of probes are mentioned in Table 1 . In brief, a total of $10 \mu \mathrm{L}$ of the reaction mixture was prepared with $1 \mathrm{X}$ TaqMan Genotyping master mix, 1X custom SNP genotyping assay, and $20 \mathrm{ng}$ of DNA from each participant. The reaction cycle was carried out in three steps as follows: step-1, initial heating at $50^{\circ} \mathrm{C}$ for $2 \mathrm{~min}$; step-2, heating at $95^{\circ} \mathrm{C}$ for $10 \mathrm{~min}$ to activate AmpliTaq gold polymerase; step-3, 40 cycles of denaturation at $94{ }^{\circ} \mathrm{C}$ for $15 \mathrm{~s}$ followed by annealing and extension at $62{ }^{\circ} \mathrm{C}$ for $1 \mathrm{~min}$. The fluorescence was read using the allele discrimination program of Applied Biosystems Realtime PCR system $(7900 \mathrm{HT})$.

\section{Enzyme-linked Immunosorbent assay}

Plasma level IL-21 was measured in patients and controls using human IL-21 Duo Set ELISA kit (R\&D Systems, Inc., USA) according to the manufacturer's instructions. All plasma samples were measured in duplicate, and the average absorbance value was recorded for a study subject. Furthermore, various autoantibodies such as Anti-cyclic citrullinated peptide (Anti-CCP: Euroimmune, Germany), anti rheumatoid factors (IgG and IgM: Abnova, Germany) were quantified by ELISA according to the instructions of the manufacturer's.

\section{Statistical analysis}

The statistics analysis was performed by GraphPad Prism version 8.3.0 (GraphPad Software, Inc., La Jolla, CA, USA). The distribution of variables was tested by the D'Agostino-Pearson omnibus normality test. Based on the normality test result, differences in IL-21 levels in RA patients and $\mathrm{HC}$ were compared by Mann Whitney $\mathrm{U}$ test. Other comparisons with more than two groups were performed with analysis of variance (ANOVA) followed by Tukey's post-test. Further, the relationship between the IL- 21 and DAS 28 scores was conducted by Spearman's correlation test. Genotype and allele frequency in RA patients and healthy controls were compared by Chi-square $\left(x^{2}\right)$ test. A $p$-value of less than 0.05 was considered statistically significant.

\section{Results}

Baseline characteristics of enrolled subjects

Baseline characteristics of rheumatoid arthritis patients and healthy controls are shown in Table 2. As demonstrated earlier, the RA is most frequent in females compared to males. In our studied cohort, female patients were 2.83 folds higher chance of having RA compared to males. Biochemicals parameters such as ESR and CRP levels were significantly elevated in RA patients compared to healthy controls. Significantly, results for subgrouping of patients based on DAS 28 score revealed that $30.3 \%$ of subjects had low disease activity (DAS 28, $<3.2$ ), whereas, $36.9 \%$ of subjects had medium (DAS 28 , 3.2-5.1) and the remaining $32.8 \%$ patients showed a high disease activity (DAS 28, >5.1). On screening of RA patients' rheumatoid factors, about $63 \%$ of patients were found positive for RF, and $62 \%$ of patients had antibodies to cyclic citrullinated peptides (CCP).

\section{RA patients displayed higher plasma IL-21 levels}

Plasma levels of IL-21 in RA patients and healthy controls were quantified by ELISA, and results are shown in Fig. 1. RA patients $(19.6 \pm 0.79 \mathrm{ng} / \mathrm{mL})$ displayed significantly higher levels of plasma IL-21 compared to healthy controls $(2.12 \pm 0.08 \mathrm{ng} / \mathrm{mL})(p<0.0001)$.

\section{Association of plasma IL-21 levels and DAS28 scores}

As the DAS28 scores represent the disease severity of rheumatoid arthritis patients, we hypothesized a possible correlation between DAS28 scores and plasma levels of

Table 1 List of probes used for genotyping of IL-21 polymorphisms

\begin{tabular}{lll}
\hline SNPs ID & code & Context sequence \\
\hline rs907715 & C_8949748_10 & VIC/FAM-AAAACAGGATTTCCTTGTTTTAACT [C/T]GCATTTATGTGATTACTAGGGAGAT \\
rs2221903 & C__16167441_10 & VIC/FAM-ACAGACAATGGGGTTITGTTTCTT [C/T]TGTTCTGCAAGCAGCAGAGCTGTGT \\
rs2055979 & C__1597496_20 & VIC/FAM-CTAACCATAACAGTTAAACAAGGTG [C/A]ATGAGATGCTAGAAATGTATGTITT \\
rs6822844 & C__28983601_10 & VIC/FAM-CCTGTCTCGCTCTCCATAGCAAAAA [G/TAGAGGACTCTTTCATGTTGCCACT \\
\hline
\end{tabular}


Table 2 Baseline characteristics of study subjects

\begin{tabular}{|c|c|c|}
\hline Parameters & $\begin{array}{l}\text { Rheumatoid arthritis } \\
\text { patients }\end{array}$ & $\begin{array}{l}\text { Healthy } \\
\text { controls }\end{array}$ \\
\hline Total numbers & 211 & 303 \\
\hline Gender (F/M) & $156 / 55$ & $210 / 93$ \\
\hline Age (Mean \pm SE) & $42.9 \pm 13.5$ & $46.1 \pm 18.3$ \\
\hline Disease duration (Months) & $18.3 \pm 9.4$ & NR \\
\hline Swollen joint counts (0-28) & 7.0 & NR \\
\hline Tender joint counts (0-28) & 13.0 & NR \\
\hline DAS28 score (\%) & & $N R$ \\
\hline$<3.2$ & 30.3 & \\
\hline Between 3.2-5.1 & 36.9 & \\
\hline$>5.1$ & 32.8 & \\
\hline SJC out of 66 & $9.4 \pm 6.3$ & NR \\
\hline ESR (mm at 1st hour) & $37.6 \pm 21.4$ & $17.8 \pm 11.2$ \\
\hline $\mathrm{CRP}(\mathrm{mg} / \mathrm{mL})$ & $18.9 \pm 22.4$ & $1.19 \pm 13.2$ \\
\hline RF positivity (\%) & 63 & NR \\
\hline Anti-CCP antibody positive (\%) & 62 & NR \\
\hline Treatment Details & & NR \\
\hline Methotrexate & $52 \%$ & \\
\hline Sulphasalazine & $46 \%$ & \\
\hline Hydroxychloroquine & $5 \%$ & \\
\hline Leflunomide & $2 \%$ & \\
\hline Tocilizumab & $12 \%$ & \\
\hline Adalimumab & $6 \%$ & \\
\hline Infliximab & $5 \%$ & \\
\hline Prednisone & $12 \%$ & \\
\hline
\end{tabular}

Data are presented as either in number, mean $\pm \mathrm{SE}$, or percentage DAS Disease Activity Score, SJC Swollen Joint Count, ESR Erythrocytic Sedimentation Rate, CRP C reactive protein, $R F$ Rheumatoid Factor, $C C P$ cyclic citrullinated protein, NR Not required

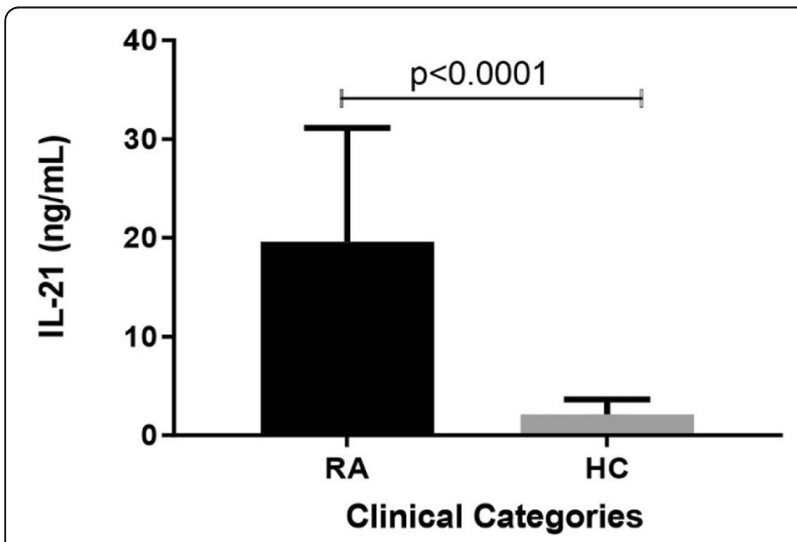

Fig. 1 Plasma IL-21 levels in subjects with RA $(n=211)$ and healthy controls $(n=303)$. Data represented the mean $\mathrm{IL}-21 \mathrm{ng} / \mathrm{mL} \pm \mathrm{SD}$ and were compared by Mann Whitney $U$ test. $P<0.05$ was deemed to be significantly positive
IL-21. Spearman rank coefficient analysis revealed a significant positive correlation between plasma IL-21 levels and DAS28 scores (spearman $r=0.61, \quad P<0.0001$ ) (Fig. 2a).

RA patients were further categorized into four subgroups based on DAS28 scores. As shown in Fig. 2b, RA patients with higher disease activity scores (DAS28 > 5.1) had higher mean plasma IL-21 levels compared to those with medium $(p<0.0001)$ and low disease activity scores $(p<0.0001)$ and remission $(p<0.0001)$. Furthermore, a significant difference in mean levels of plasma IL-21 was observed among the lower and intermediate disease activity group $(p<0.0001)$ (Fig. $2 b)$.

IL-21 has been linked with increased follicular T cells, elevated B cell activation, proliferation, and production of antibodies [27]. Further, IL-21 levels are positively correlated with disease activity scores in rheumatoid arthritis patients [27]. However, no significant correction was observed among IL-21 and anti-CCP, RF-IgG, and RF-IgM levels in the present study (data not shown).

\section{Distribution of IL-21 polymorphisms in the healthy Chinese population}

A total of 303 healthy Chinese subjects were genotyped for four common SNPs (rs907715, rs2221903, rs2055979, and rs6822844) TaqMan genotyping method. All subjects were having major genotype (GG) for rs6822844 polymorphism [17]. As shown in Table 3, heterozygous mutants were more frequent in rs907715 and rs2055979 polymorphism, followed by wild type and homozygous mutant. Further, for rs2221903 polymorphism, the wildtype remained highly prevalent compared to heterozygous (23\%) and homozygous mutant (2\%). Distribution of genotypes for three SNPs were in HardyWeinberg Equilibrium (HWE) (rs907715: $\mathrm{X}^{2}=0.01, p=$ 0.90, rs2221903: $X^{2}=0.04, p=0.82$, rs2055979: $X^{2}=0.18$, $p=0.66)$.

\section{Association of IL-21 rs2055979 polymorphism with susceptibility to RA}

To test whether common genetic variants in the IL-21 gene are associated with predisposition to rheumatoid arthritis development, we genotyped rs907715, rs2221903 rs2055979 polymorphism in 211 RA patients and 303 healthy controls. As shown in Table 3, the prevalence of homozygous mutant (AA) of rs2055979 polymorphism was significantly higher in RA patients compared to healthy controls $\left(p<0.0001, x^{2}=34.73\right.$, $\mathrm{OR}=4.342)$. The frequency of mutants $(\mathrm{CA}+\mathrm{AA})$ was also higher in RA than in controls $\left(p=0.001, \chi^{2}=10.71\right.$, $\mathrm{OR}=1.901)$. Furthermore, the mutant allele $(\mathrm{A})$ was even more frequent in patients than healthy controls $\left(p<0.0001, \quad x^{2}=35.53, \quad \mathrm{OR}=2.149\right), \quad$ indicating an 

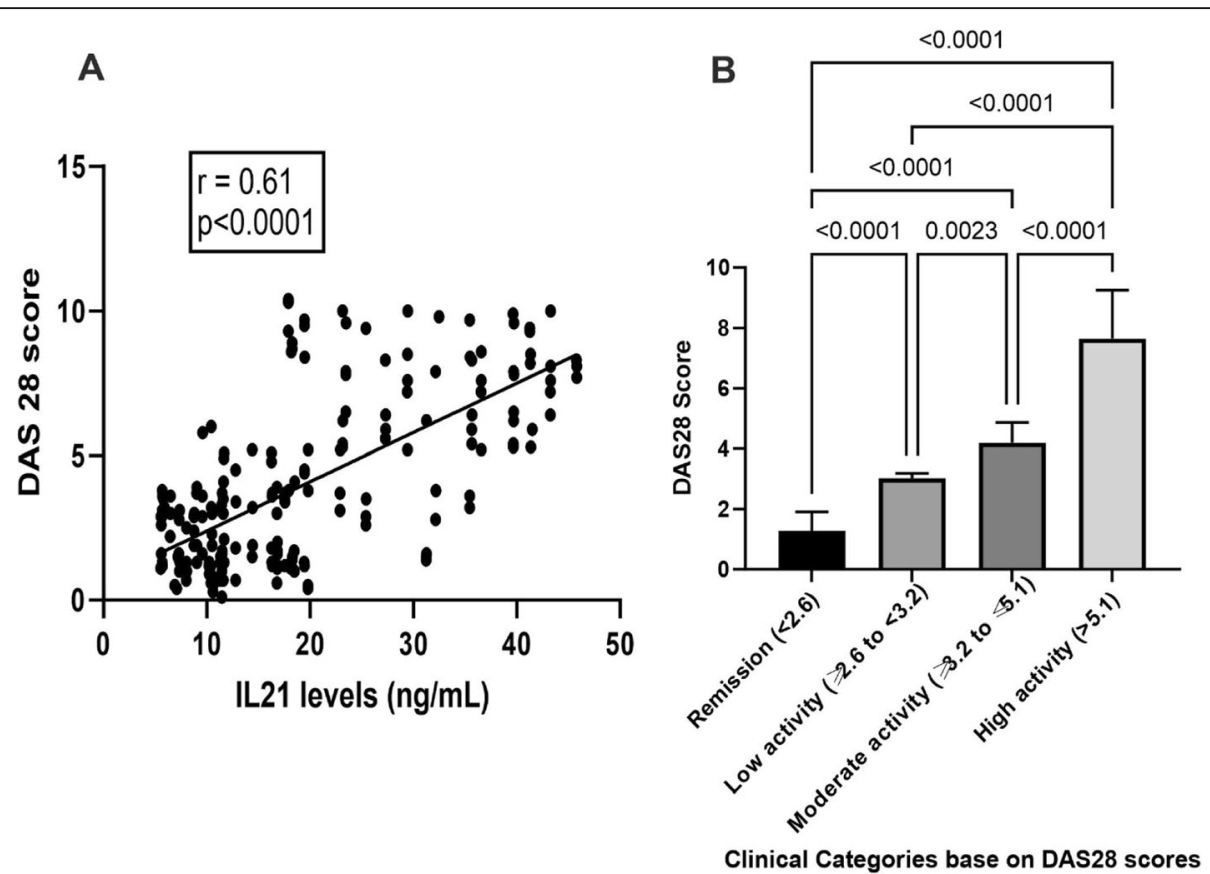

Fig. 2 Correlation between plasma IL-21 level with DAS score. IL-21 levels were measured by ELISA in all RA patients and correlated with the DAS score of RA patients. A positive correlation was observed among IL-21 levels and DAS scores (a). Further, RA subjects were subcategorized in to four groups based on DAS scores such as remission [DAS $28<2.6(n=52)$ ], low activity [DAS 28, $\geq 2.6$ to $<3.2(n=12)$ ], medium activity [DAS 28 , $\geq 3.2$ to $\leq 5.1(n=79)]$ and high activity [DAS 28, $>5.1(n=68)]$. Data represented the mean of IL-21 levels $(\mathrm{ng} / \mathrm{mL}) \pm$ SD and were compared using ANOVA with Tukey's post-test. A P-value of less than 0.05 was taken as statistically significant

essential genetic susceptible factor on predisposition to RA development.

Functional relevance of IL-21 rs2055979 polymorphism Plasma levels of IL-21 in RA patients and healthy controls were analyzed among different genotypes of IL-21 polymorphisms (rs907715, rs2221903, and rs2055979) to investigate the possible association plasma IL-21 levels. As shown in Fig. 3a, the AA genotype of rs2055979 polymorphisms had higher plasma levels of IL-21 than other genotypes, i.e., CA demonstrated intermediate levels, and CC had the lowest levels of plasma IL-21. Interestingly, similar observations were noticed when the association of IL-21 rs2055979 polymorphism was analyzed in RA patients (Fig. 3b) and healthy controls (Fig. 3c). For other studied SNPs (rs907715 and rs2221903), no significant association between genotypes and plasma levels of IL-21 was observed (data not shown).

\section{Association of IL-21 rs2055979 polymorphism with DAS28 scores}

As DAS 28 and plasma levels of IL-21 were correlated; further, we analyzed the possible association of IL-21 polymorphisms with DAS28 scores. As shown in Fig. 4c, we observed a significant association between IL-21 rs2055979 polymorphism with DAS28 scores: subjects with AA genotyped had higher DAS28 scores than CA and CC genotypes. However, such association was not observed in rs907715 and rs2221903 polymorphisms (Fig. 4a and b).

\section{Discussion}

The role of different cytokines in mediating the pathogenesis of rheumatic diseases has been well documented. Prior reports suggested that some cytokines secreted by Th1, Th2, and Th17 cells have been designated as potent biomarkers in RA's pathogenesis [28]. Studies in Chinese RA patients are limited. A report during 2011-2012 indicated the significance of chemokines, pro and antiinflammatory cytokines RA [29]. In the Chinese population, however, the role of IL-21 in RA pathogenesis has never been critically studied.

In the present investigation, we observed a significantly elevated plasma IL-21 in Chinese patients with RA compared to healthy controls. These results are corroborated with previous reports. An earlier hospitalbased case-control study in Chinese patients demonstrated higher serum IL-21 levels than healthy controls [30]. Similarly, in a longitudinal study in patients with early-stage RA, IL-21 level was upregulated in diseased subjects compared to controls [31]. All of these findings, including our results, indicated the possible function of IL-21 in the advancement of RA pathogenesis. 
Table 3 Prevalence of IL-21 polymorphisms among controls and RA patients

\begin{tabular}{|c|c|c|c|c|c|c|}
\hline Polymorphisms & Genotype or Allele & $\mathrm{HC}(n=303)$ & $\mathrm{RA}(n=211)$ & $P$-value & $x^{2}$ value & OR $(95 \% \mathrm{CI})$ \\
\hline \multirow[t]{8}{*}{ rs907715 C> T } & Genotype & & & & & \\
\hline & CC & $91(30)$ & $68(32)$ & 1 & & ref \\
\hline & $C T$ & $151(50)$ & $103(49)$ & 0.656 & 0.197 & 0.912 (0.613 to 1.366$)$ \\
\hline & $\pi$ & $61(20)$ & $40(19)$ & 0.613 & 0.254 & 0.877 (0.525 to 1.444$)$ \\
\hline & $\mathrm{CT}+\mathrm{TT}$ & $212(70)$ & $143(68)$ & 0.596 & 0.280 & 0.902 (0.622 to 1.319$)$ \\
\hline & Allele & & & & & \\
\hline & C & $333(55)$ & $239(57)$ & 1 & & ref \\
\hline & T & $273(45)$ & $183(43)$ & 0.592 & 0.286 & 0.934 (0.724 to 1.202 ) \\
\hline \multicolumn{7}{|l|}{ rs2221903 T>C } \\
\hline & $\pi$ & $227(75)$ & $154(73)$ & 1 & & ref \\
\hline & TC & $70(23)$ & $49(23)$ & 0.883 & 0.021 & 1.032 (0.676 to 1.581$)$ \\
\hline & CC & $6(2)$ & $8(4)$ & 0.211 & 1.561 & 1.965 (0.658 to 5.779 ) \\
\hline & $\mathrm{TC}+\mathrm{CC}$ & $76(25)$ & $57(27)$ & 0.622 & 0.242 & 1.106 (0.738 to 1.635$)$ \\
\hline & Allele & & & & & \\
\hline & T & $524(86)$ & $357(85)$ & 1 & & ref \\
\hline & $C$ & $82(14)$ & $65(15)$ & 0.399 & 0.711 & 1.163 (0.822 to 1.655$)$ \\
\hline \multirow[t]{8}{*}{ rs2055979 C > A } & Genotype & & & & & \\
\hline & $\mathrm{CC}$ & 118 (39) & $53(25)$ & 1 & & ref \\
\hline & CA & $145(48)$ & $80(38)$ & 0.341 & 0.906 & 1.228 (0.811 to 1.888$)$ \\
\hline & AA & $40(13)$ & $78(37)$ & $<0.0001$ & 34.73 & 4.342 (2.623 to 7.219$)$ \\
\hline & $C A+A A$ & $185(61)$ & $158(75)$ & 0.001 & 10.71 & 1.901 (1.301 to 2.796$)$ \\
\hline & Allele & & & & & \\
\hline & $C$ & $381(63)$ & $186(44)$ & 1 & & ref \\
\hline & A & $225(37)$ & $236(56)$ & $<0.0001$ & 35.53 & 2.149 (1.662 to 2.766$)$ \\
\hline
\end{tabular}

Note: Data of HC and RA are in the number of subjects (\%) format, $H C$ healthy controls, RA rheumatoid arthritis patients

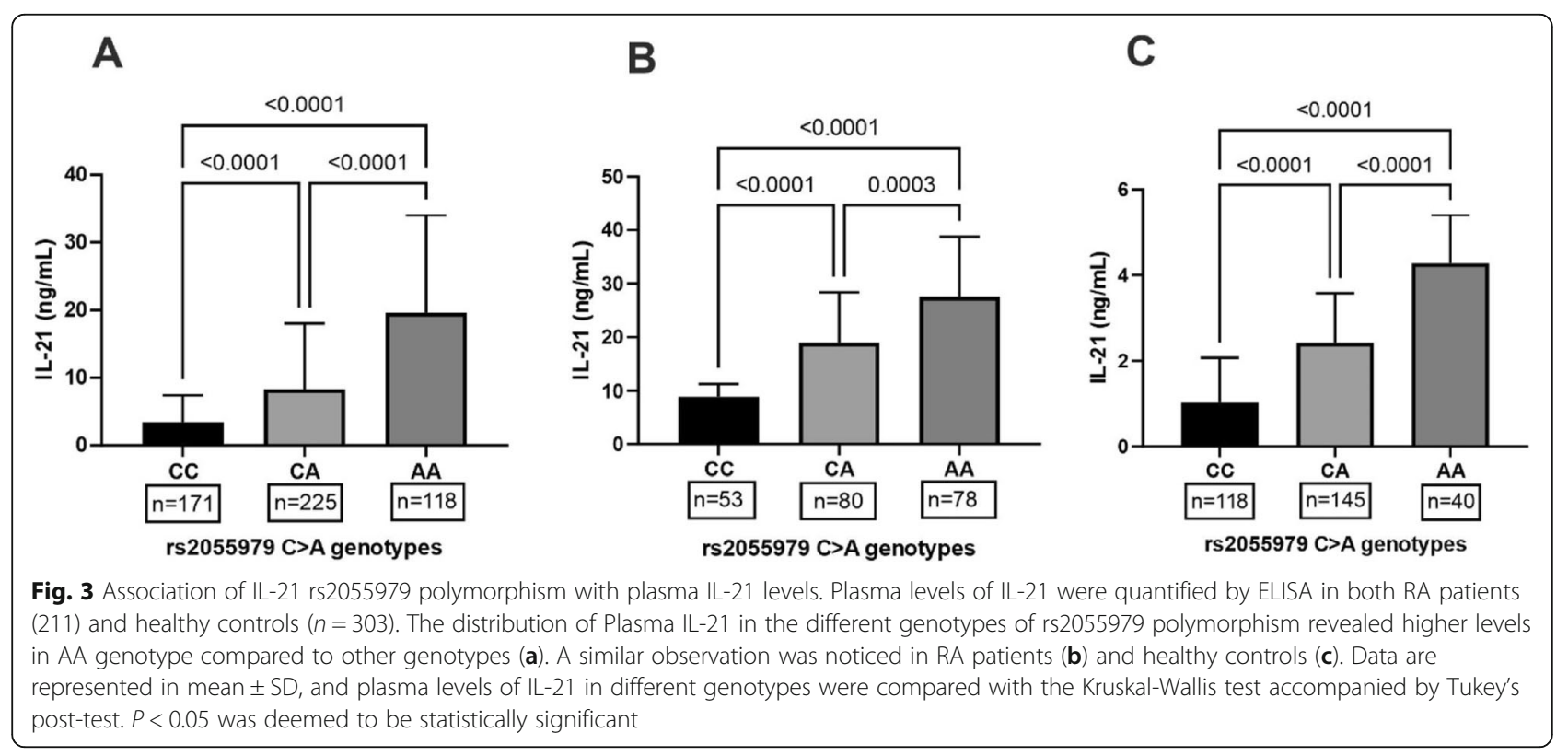



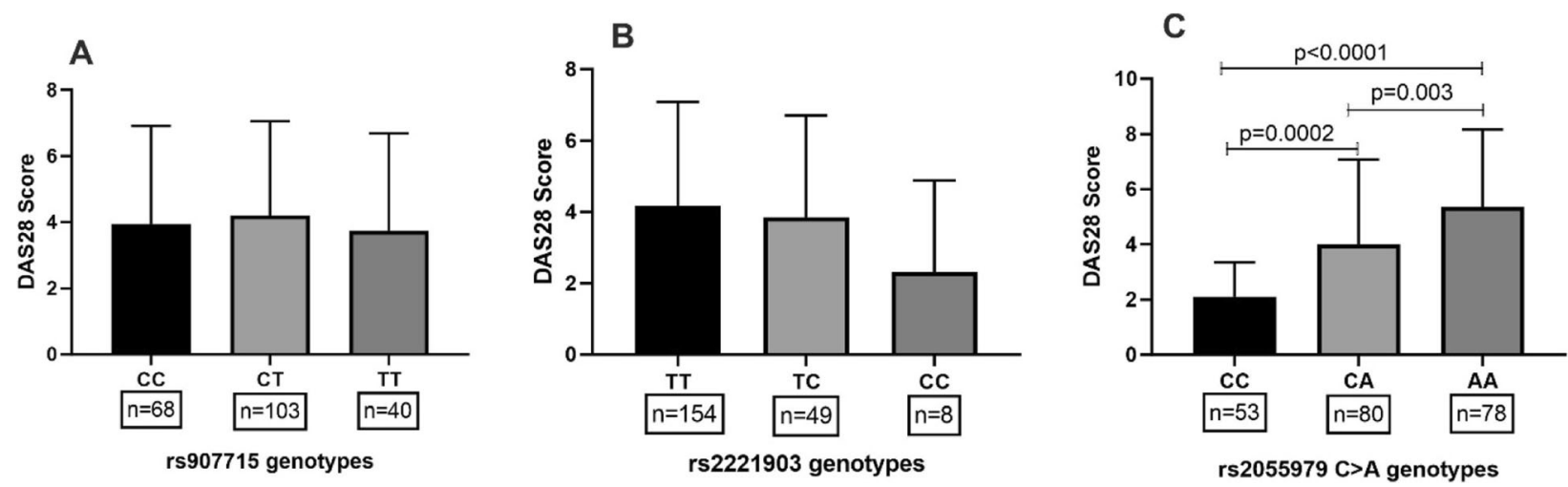

Fig. 4 Association of IL-21 gene polymorphisms (rs907715, rs2221903, and rs2055979) with DAS28 scores. The DAS28 score was comparable in different genotypes of rs907715 (a) and rs2221903 (b) polymorphism. A significant difference was noticed in rs2055979 polymorphism with DAS28 scores. AA genotype was associated with higher DAS28 scores compared to other genotypes (c). Data are represented in the mean \pm SD, and plasma levels of IL-21 in different genotypes were compared with ANOVA accompanied by Tukey's post-test. $P<0.05$ was deemed to be statistically significant

Nevertheless, controversial results do still occur. There was no substantial difference in serum IL-21 level between subjects with recent RA onset and healthy controls in a study by Sglundaet al [32]. Furthermore, in rheumatoid arthritis patients with higher disease activity (DAS28 > 5.1) and healthy control levels, IL-21 levels were also comparable [32]. Although the exact reason for such discrepancy in data is not known, the use of fewer patients $(n=51)$ in the given study may be a contributing factor.

An independent study [32] have highlighted comparable IL-21 levels between high disease activity (DAS28, $>5.1$ RA patients and healthy subjects. On the contrary, we observed a significantly higher level of IL-21 in the patient group with DAS $28>5.1$ compared to the other three groups (DAS2 $<<2.6$, DAS2 $2 \geq 2.6$ to $<3.2$, and DAS28 3.2-5.1) and healthy controls. In line with these findings, higher plasma levels of IL- 6 and IFN- $\alpha$ were recorded in rheumatoid patients with higher disease activity than those with lower DAS28 scores [33].

In our current research, a steady rise in plasma IL-21 in the higher disease activity of the patients was observed. This finding led us to investigate further the possible link between the plasma IL-21 levels and DAS 28 scores. A positive association between IL-21 and DAS28 was observed, corroborating earlier observations [27, 32]. However, another study found no connection between IL-21 and DAS 28 in 126 Chinese RA patients [30].

The role of IL-21 in the pathogenesis of rheumatoid arthritis is well investigated. IL-21 is mostly secreted by $\mathrm{T}$ helper 17 cells (Th17), follicular $\mathrm{T}$ helper cells (Tfh), and natural killer cells (NKT) [34]. IL-21 facilitates the activation of B cells, NK cells, and the production of antibodies. The IL-21 receptor (IL-21R), which recognizes IL-21 as a ligand, is highly expressed on CD4+ T cells on macrophages and dendric cells in RA patients [35]. Cells expressing IL-21R recognizes IL-21 and respond through MAPK, PI3K/AKT, and JAK-STAT pathways [34]. Several reports in the mouse model also further strengthen the importance of IL-21 in RA. Administration of IL-21 receptor Fc fusion protein (IL$21 R F c)$, a neutralizing agent of IL-21 in the arthritis model, significantly diminished IL-6 and IL-17 [16]. Furthermore, injection of IL-21RFc in collagen-induced arthritis significantly reduced the disease progression [16]. Besides, RA synovial cell culture with IL-21RFc significantly reduces the production of TNF- $\alpha$, IL- 6 , and IL-1 $\beta$ [36].

The association of IL-21 polymorphisms with a predisposition to RA development has been extensively investigated in different populations. In most of the research, the role of rs6822844 polymorphism was investigated to find a potential link with the susceptibility to the development of RA. Reports including RA patients from different geographical regions showed the protective role of the rs6822844 variant against RA development in the Netherlands [21], Algerian [22], Columbian [19] population. The latest meta-analysis further strengthens individual case-control observation [23]. However, both patients and controls were wild types for rs6822844 polymorphism, similar to an earlier study in the Chinese population [17]. Collectively these observations indicate the absence of rs6822844 variants in the Chinese population.

In this study, we observed a significant role in rs2055979 polymorphism with RA predisposition. Subjects carrying the genotype of AA had a 4.34-fold higher susceptibility to RA. However, the distribution of other common polymorphisms among healthy controls and RA patients was comparable. Earlier research in Chinese 
systemic lupus erythematosus patients recorded similar observations: rs2055979 was correlated with susceptibility, whereas rs 907715 and rs2221903 polymorphisms did not play a significant role [17]. Similarly, in an earlier study, rs907715 polymorphism failed to associate RA susceptibility in the Australian population [37]. Besides, an essential functional significance of rs2055979 polymorphism was noted in the present report: subjects with AA genotype had higher plasma IL-21 than those with CC genotype. Interestingly, heterozygotes demonstrated intermediate levels of Il-21. Similar association trends have been observed in both healthy control and RA patients. In line with our findings, an earlier study showed a substantial difference in AA and CC genotype plasma IL-21 levels. However, differences between heterozygous and wild or homozygous mutants could not be detected, likely due to the limited sample size. The mechanism of how the AA genotype is correlated with higher IL-21 levels is not understood. The SNP rs2055979 is located in the intronic region and may have an impact on the splicing process [38].

Although we have included a larger cohort of healthy controls and RA patients and demonstrated the importance of IL-21 in the present investigation, the present report has several limitations. First, all patients included in the study were not naïve, and most of them were treated before enrollment in the study, which may affect the patients' clinical parameters. Second, in the present report, we have considered only four SNPs in the IL-21 gene. Thus, other functional SNPs in the IL-21 gene may be studied in the future. Third, the samples enrolled in the investigation were hailed from Shanghai and adjacent areas. It would be interesting to replicate the study in other populations.

In conclusion, IL-21 plasma levels are increased in patients with rheumatoid arthritis associated with disease severity. Furthermore, IL-21 (rs2055979) mutant is associated with elevated IL-21 plasma levels and is predisposed to RA development. However, further studies are required in different populations to validate our findings.

\section{Acknowledgments}

Authors would like to thanks all participants of the present report.

\section{Authors' contributions}

YZ: Investigation, laboratory experiments, formal analysis; LX: Investigation, laboratory experiments; JX: Investigation, formal analysis; ZL: Investigation, formal analysis; BY: Investigation, formal analysis; MZ: conceptualization, supervision, writing original draft, review and editing. The author(s) read and approved the final manuscript.

\section{Funding}

This study was supported by the Research Project on Community Medicine and Health Management of Shanghai. The study was supported by The Key Funding Projects for Independent Innovation of Health System Research in Putuo District, Shanghai. (SH201741); Wuhan Municipal Health and Family Planning Commission's Scientific Research Project Task Book (WG16D01). Shanghai Putuo District clinical characteristic construction project
(No:2019tszk01); Shanghai Association of the Integration of Traditional and Western Medicine (No:SH201741); Independent Innovation of Health System Research (No:ptkwws201708).

Availability of data and materials

Data will be available upon request to the corresponding author.

\section{Declarations}

\section{Ethics approval and consent to participate}

The study protocol was approved by the Institutional Human Ethical Committee of Shanghai Putuo People's Hospital (PTRMYY20200826), and written informed consent was obtained from each participant.

\section{Consent for publication}

Not Applicable.

\section{Competing interests}

Authors declare no conflict in interest.

\section{Author details}

'Department of Rehabilitation, Shanghai Putuo People's Hospital, Putuo People's Hospital Affiliated to Tongji University, Shanghai 200060, China. ${ }^{2}$ Department of Rehabilitation Medicine, The Third Affiliated Hospital of Sun Yat-sen University, Guangzhou 510630, China. ${ }^{3}$ Southern Medical University, Guangzhou 510515, Guangdong, China. ${ }^{4}$ Department of Rehabilitation Medicine, The First People's Hospital of Foshan, Foshan 528000, Guangdong, China. ${ }^{5}$ Department of Chinese Medicine, Wuhan Fourth Hospital, Puai Hospital, Tongji Medical College, Huazhong University of Science and Technology, Wuhan, Hubei 430033, China.

Received: 12 November 2020 Accepted: 8 February 2021

Published online: 05 March 2021

\section{References}

1. Myasoedova E, Davis JM 3rd, Crowson CS, Gabriel SE. Epidemiology of rheumatoid arthritis: rheumatoid arthritis and mortality. Curr Rheumatol Rep. 2010;12(5):379-85.

2. Scott DL, Wolfe F, Huizinga TW. Rheumatoid arthritis. Lancet. 2010; 376(9746):1094-108

3. Shoda H, Nagafuchi Y, Tsuchida Y, Sakurai K, Sumitomo S, Fujio K, Yamamoto K. Increased serum concentrations of IL-1 beta, IL-21 and Th17 cells in overweight patients with rheumatoid arthritis. Arthritis Res Ther. 2017;19(1):111.

4. Brennan FM, Mclnnes IB. Evidence that cytokines play a role in rheumatoid arthritis. J Clin Invest. 2008;1 18(11):3537-45.

5. Firestein GS, McInnes IB. Immunopathogenesis of rheumatoid arthritis. Immunity. 2017:46(2):183-96.

6. McInnes IB, Schett G. Pathogenetic insights from the treatment of rheumatoid arthritis. Lancet. 2017;389(10086):2328-37.

7. Burmester GR, Pope JE. Novel treatment strategies in rheumatoid arthritis. Lancet. 2017;389(10086):2338-48.

8. Spolski R, Leonard WJ. Interleukin-21: a double-edged sword with therapeutic potential. Nat Rev Drug Discov. 2014;13(5):379-95.

9. Leonard WJ, Wan CK. IL-21 Signaling in Immunity. F1000Research. 2016;5.

10. Yi JS, Cox MA, Zajac AJ. Interleukin-21: a multifunctional regulator of immunity to infections. Microbes Infect. 2010;12(14-15):1111-9.

11. Monteleone G, Sarra M, Pallone F. Interleukin-21 in T cell-mediated diseases. Discov Med. 2009;8(42):113-7.

12. Niu X, He D, Zhang X, Yue T, Li N, Zhang JZ, Dong C, Chen G. IL-21 regulates Th17 cells in rheumatoid arthritis. Hum Immunol. 2010;71(4):33441.

13. Ozaki K, Spolski R, Feng CG, Qi CF, Cheng J, Sher A, Morse HC 3rd, Liu C, Schwartzberg PL, Leonard WJ. A critical role for IL-21 in regulating immunoglobulin production. Science. 2002;298(5598):1630-4.

14. Jungel A, Distler JH, Kurowska-Stolarska M, Seemayer CA, Seibl R, Forster A, Michel BA, Gay RE, Emmrich F, Gay S, et al. Expression of interleukin-21 receptor, but not interleukin-21, in synovial fibroblasts and synovial macrophages of patients with rheumatoid arthritis. Arthritis Rheum. 2004; 50(5):1468-76. 
15. Kwok SK, Cho ML, Park MK, Oh HJ, Park JS, Her YM, Lee SY, Youn J, Ju JH, Park KS, et al. Interleukin-21 promotes osteoclastogenesis in humans with rheumatoid arthritis and in mice with collagen-induced arthritis. Arthritis Rheum. 2012;64(3):740-51.

16. Young DA, Hegen M, Ma HL, Whitters MJ, Albert LM, Lowe L, Senices M, Wu PW, Sibley B, Leathurby $Y$, et al. Blockade of the interleukin-21/interleukin-21 receptor pathway ameliorates disease in animal models of rheumatoid arthritis. Arthritis Rheum. 2007;56(4):1152-63.

17. Lan Y, Luo B, Wang $\mathrm{J}$, Jiang YW, Wei YS. The association of interleukin-21 polymorphisms with interleukin-21 serum levels and risk of systemic lupus erythematosus. Gene. 2014;538(1):94-8.

18. Jia HY, Zhang ZG, Gu XJ, Guo T, Cui B, Ning G, Zhao YJ. Association between interleukin 21 and Graves' disease. Genet Mol Res. 2011;10(4): 3338-46.

19. Maiti AK, Kim-Howard X, Viswanathan P, Guillén L, Rojas-Villarraga A, Deshmukh H, Direskeneli H, Saruhan-Direskeneli G, Cañas C, Tobön GJ, et al. Confirmation of an association between rs6822844 at the II2-II21 region and multiple autoimmune diseases: evidence of a general susceptibility locus. Arthritis Rheum. 2010;62(2):323-9.

20. Márquez A, Orozco G, Martínez A, Palomino-Morales R, Fernández-Arquero M, Mendoza JL, Taxonera C, Díaz-Rubio M, Gómez-García M, Nieto A, et al. Novel association of the interleukin 2-interleukin 21 region with inflammatory bowel disease. Am J Gastroenterol. 2009;104(8):1968-75.

21. Daha NA, Kurreeman FA, Marques RB, Stoeken-Rijsbergen G, Verduijn W, Huizinga TW, Toes RE. Confirmation of STAT4, IL2/IL21, and CTLA4 polymorphisms in rheumatoid arthritis. Arthritis Rheum. 2009;60(5):1255-60.

22. Louahchi S, Allam I, Raaf N, Berkani L, Boucharef A, Abdessemed A, Khaldoun N, Bahaz N, Ladjouze-Rezig A, Nebbab A, et al. Association of rs6822844 within the KIAA1109/TENR/IL2/IL21 locus with rheumatoid arthritis in the Algerian population. Hla. 2016;87(3):160-4.

23. Yu M, Hou J, Zheng M, Cao Y, Alike Y, Mi Y, Zhu J. IL-21 gene rs6822844 polymorphism and rheumatoid arthritis susceptibility. Biosci Rep. 2020;40(1).

24. Aletaha D, Neogi T, Silman AJ, Funovits J, Felson DT, Bingham CO 3rd, Birnbaum NS, Burmester GR, Bykerk VP, Cohen MD, et al. 2010 rheumatoid arthritis classification criteria: an American College of Rheumatology/ European League Against Rheumatism collaborative initiative. Ann Rheum Dis. 2010;69(9):1580-8.

25. van Gestel $A M$, Prevoo ML, van't Hof MA, van Rijswijk $M H$, van de Putte $L B$, van Riel PL. Development and validation of the European League Against Rheumatism response criteria for rheumatoid arthritis. Comparison with the preliminary American College of Rheumatology and the World Health Organization/International League Against Rheumatism Criteria. Arthritis Rheum. 1996:39(1):34-40.

26. World Medical A. World medical association declaration of Helsinki: ethical principles for medical research involving human subjects. J Postgrad Med. 2002:48(3):206-8.

27. Liu R, Wu Q, Su D, Che N, Chen H, Geng L, Chen J, Chen W, Li X, Sun L. A regulatory effect of $\mathrm{IL}-21$ on $T$ follicular helper-like cell and $B$ cell in rheumatoid arthritis. Arthritis Res Ther. 2012;14(6):R255.

28. Burska A, Boissinot M, Ponchel F. Cytokines as biomarkers in rheumatoid arthritis. Mediat Inflamm. 2014:2014:545493.

29. Xia T, Zheng XF, Qian BH, Fang H, Wang JJ, Zhang LL, Pang YF, Zhang J, Wei XQ, Xia ZF, et al. Plasma Interleukin-37 is elevated in patients with rheumatoid arthritis: its correlation with disease activity and Th1/Th2/Th17related cytokines. Dis Markers. 2015;2015:795043.

30. Xing R, Sun L, Wu D, Jin Y, Li C, Liu X, Zhao J. Autoantibodies against interleukin-21 correlate with disease activity in patients with rheumatoid arthritis. Clin Rheumatol. 2018:37(1):75-80.

31. Agonia I, Couras J, Cunha A, Andrade AJ, Macedo J, Sousa-Pinto B. IL-17, IL21 and IL-22 polymorphisms in rheumatoid arthritis: a systematic review and meta-analysis. Cytokine. 2020;125:154813.

32. Sglunda O, Mann HF, Hulejova H, Pecha O, Plestilova L, RuZickova O, Fojtikova M, Sleglova O, Forejtova S, Pavelka K, et al. Decrease in serum interleukin-21 levels is associated with disease activity improvement in patients with recent-onset rheumatoid arthritis. Physiol Res. 2014;63(4):47581.

33. Milman N, Karsh J, Booth RA. Correlation of a multi-cytokine panel with clinical disease activity in patients with rheumatoid arthritis. Clin Biochem 2010;43(16-17):1309-14.

34. Leonard WJ, Wan C-K. IL-21 Signaling in Immunity. F1000Research. 2016;5: F1000 Faculty Rev-1224.
35. Habib T, Nelson A, Kaushansky K. IL-21: a novel IL-2-family lymphokine that modulates B, T, and natural killer cell responses. J Allergy Clin Immunol. 2003;112(6):1033-45.

36. Andersson AK, Feldmann M, Brennan FM. Neutralizing IL-21 and IL-15 inhibits pro-inflammatory cytokine production in rheumatoid arthritis. Scand J Immunol. 2008;68(1):103-11.

37. Hollis-Moffatt JE, Chen-Xu M, Topless R, Dalbeth N, Gow PJ, Harrison AA, Highton J, Jones PB, Nissen M, Smith MD, et al. Only one independent genetic association with rheumatoid arthritis within the KIAA1109-TENR-IL2IL21 locus in Caucasian sample sets: confirmation of association of rs6822844 with rheumatoid arthritis at a genome-wide level of significance. Arthritis Res Ther. 2010;12(3):R116.

38. Anna A, Monika G. Splicing mutations in human genetic disorders: examples, detection, and confirmation. J Appl Genet. 2018;59(3):253-68.

\section{Publisher's Note}

Springer Nature remains neutral with regard to jurisdictional claims in published maps and institutional affiliations.

\section{Ready to submit your research? Choose BMC and benefit from:}

- fast, convenient online submission

- thorough peer review by experienced researchers in your field

- rapid publication on acceptance

- support for research data, including large and complex data types

- gold Open Access which fosters wider collaboration and increased citations

- maximum visibility for your research: over $100 \mathrm{M}$ website views per year

At $\mathrm{BMC}$, research is always in progress.

Learn more biomedcentral.com/submissions 